\title{
Um estudo sobre a identidade profissional de futuros professores de Matemática no Estágio Curricular Supervisionado
}

\author{
Cirléia Pereira Barbosa \\ Celi Espasandin Lopes
}

\begin{abstract}
Resumo: Este artigo tem como objetivo analisar os indícios constitutivos da identidade profissional de futuros professores de Matemática ao participarem de um grupo de estudos no âmbito do Estágio Curricular Supervisionado. A pesquisa, de cunho qualitativo, foi realizada em 2019 numa escola pública de Formiga (MG) e contou com a participação de dois alunos de um curso de Licenciatura em Matemática e seus supervisores de Estágio. Os dados discutidos neste texto foram produzidos por meio de narrativas escritas dos estagiários, gravações em áudio e vídeo dos encontros, avaliação e autoavaliação feita pelos licenciandos. As experiências formativas, vivenciadas pelos licenciandos nos estágios e no grupo de estudos, contribuíram para a manifestação de aspectos da identidade docente, como: emoção, autoconhecimento, autonomia e compromisso político. Também evidenciaram a importância de contextos formativos para 0 desenvolvimento da identidade profissional.
\end{abstract}

Palavras-chave: Educação Matemática. Formação inicial de professores de Matemática. Estágio Curricular Supervisionado. Identidade profissional.

\section{A study on the professional identity of future Mathematics teachers in Supervised Curricular Internship}

Abstract: This paper aims to analyze the evidence that constitutes the professional identity of future mathematics teachers when participating in a study group within the scope of the Supervised Curricular Internship. The qualitative research was carried out in 2019 at a public school in Formiga (MG), and included the participation of two students from a Mathematics Degree course and their Internship supervisors. The data discussed in this text were produced through written narratives of the interns, audio and video recordings of the meetings, evaluation and self-evaluation made by the undergraduate students. The formative experiences, experienced by the graduates in the internships and in the study group, contributed to the manifestation of aspects of the teacher identity, such as: emotion, self-knowledge, autonomy and political commitment. The results show the importance of formative contexts for the development of professional identity.

Keywords: Mathematics Education. Mathematics Teachers Education. Supervised Curricular Internship. Professional identity.

\section{Un estudio sobre la identidad profesional de los futuros maestros de Matemáticas en la Práctica Curricular Supervisada}

Resumen: Este artículo tiene como objetivo analizar la evidencia constitutiva de la identidad 
profesional de los futuros maestros de Matemáticas al participar en un grupo de estudio dentro del alcance de la Práctica Curricular Supervisada. La investigación cualitativa se llevó a cabo en 2019 en una escuela pública en Formiga (MG), con la participación de dos estudiantes de un curso de Licenciatura en Matemáticas y sus supervisores de pasantías. Los datos discutidos en este texto fueron producidos a través de narraciones escritas de los pasantes, grabaciones de audio y video de las reuniones, evaluación y autoevaluación realizadas por los estudiantes de pregrado. Las experiencias formativas, experimentadas por los graduados en las pasantías y en el grupo de estudio, contribuyeron a la manifestación de aspectos de la identidad docente, tales como: emoción, autoconocimiento, autonomía y compromiso político. También destacaron la importancia de los contextos formativos para el desarrollo de la identidad profesional.

Palabras clave: Educación Matemática. Formación inicial de profesores de Matemáticas. Prácticas supervisadas. Identidad professional.

\section{Introdução}

Este texto apresenta parte de uma pesquisa de doutorado que analisa os saberes docentes mobilizados e redimensionados por futuros professores de Matemática, ao participarem de um grupo de estudos no âmbito do Estágio Curricular Supervisionado, e os indícios constitutivos da sua identidade profissional que emergem dessa experiência. Para realizar a investigação, constituímos um grupo de estudos com dois licenciandos em Matemática, seus professores supervisores de Estágio e a pesquisadora - primeira autora deste manuscrito. Na tese, que está sendo construída a partir dessa pesquisa, analisamos os saberes e os aspectos que constituem a identidade profissional docente dos futuros professores e o movimento do grupo a partir dos encontros. No recorte dado a este artigo, apresentaremos a análise dos indícios constitutivos da identidade profissional docente dos licenciandos em Matemática, revelados em suas reflexões sobre as experiências vivenciadas no Estágio.

É importante esclarecer, em consonância com Pimenta e Lima (2012), que o tipo de estágio referido em nossa pesquisa é o Estágio Curricular Supervisionado, entendido como um campo de conhecimento que integra o processo de formação do licenciando. Nele, o campo de atuação é tomado pelo futuro professor como objeto de estudo, de investigação, de análise e de interpretação crítica, a partir do que é estudado nas disciplinas do curso. Diferente do estágio profissional, que busca inserir o estudante no campo de trabalho com o objetivo de treinar as rotinas de atuação.

Nessa direção, o Estágio pode tornar-se um campo de conhecimento e de pesquisa que possibilita a construção da identidade profissional do futuro professor (PIMENTA e LIMA, 2012).

Uma das finalidades do Estágio na formação inicial de professores é possibilitar 
problematizações e reflexões sobre a escola, a sala de aula, os conteúdos disciplinares a serem abordados, os processos de ensinar e aprender, dentre outros. Nessa perspectiva, o Estágio Curricular Supervisionado configura-se como um espaço privilegiado da aprendizagem da docência e do desenvolvimento da identidade profissional, e pode contribuir para "catalisar reflexões sobre a docência e minimizar a ruptura entre a formação inicial e a entrada na carreira" (CARNEIRO, 2015, p. 3).

Também é no Estágio Curricular Supervisionado que os alunos da formação inicial — seja licenciatura em Matemática ou Pedagogia — têm a oportunidade de fazer uma leitura da profissão docente não mais na condição de aluno, mas como aprendiz da profissão; configura-se, portanto, um momento de transição de aluno a professor.

Nos cursos de Licenciatura em Matemática, o Estágio Curricular Supervisionado pode se constituir em um espaço privilegiado de formação do futuro professor ao oportunizar a articulação entre os conhecimentos teóricos e os conteúdos matemáticos ensinados na escola. 0 documento da Sociedade Brasileira de Educação Matemática (SBEM), que apresenta contribuições para discussões a respeito de propostas para tais cursos, ressalta essa articulação entre o estudo teórico e os saberes práticos, ao considerar que

\footnotetext{
o Estágio Supervisionado não pode se configurar como espaço isolado, fechado em si mesmo e desarticulado do restante do curso, mas sim como espaços em que os professores em formação vão colocando em uso os conhecimentos que aprendem, ao mesmo tempo em que possam mobilizar outros, de diferentes naturezas e oriundos de diferentes experiências, nos diferentes tempos e espaços curriculares (SBEM, 2003, p. 22).
}

Assim, o Estágio Curricular Supervisionado é um momento importante no desenvolvimento profissional do futuro professor de Matemática. Se bem explorado, torna-se uma rica oportunidade de articular os conhecimentos e experiências - como estudante - a partir de um olhar diferenciado - de futuro professor - sobre a escola e a sala de aula, e com toda bagagem teórico-prática do curso de Licenciatura em Matemática (LOPES, TRALDI JR. e FERREIRA, 2015). Também, auxiliar na transição de aluno (licenciando) para profissional (professor), minimizando possíveis dilemas e tensões comuns no início da carreira docente.

Em nossa pesquisa, assim como Teixeira e Cyrino (2015b), consideramos a formação inicial como uma das etapas do processo de desenvolvimento profissional dos futuros professores de Matemática. Esse processo é resultado de uma experiência capaz de propiciar mudanças nas 
crenças, conhecimentos e práticas de professores e futuros professores relativas à sua profissão e tem como meta a constituição da identidade profissional (CYRINO, 2013).

Neste artigo, temos como objetivo analisar os indícios constitutivos da identidade profissional docente, manifestados por futuros professores de Matemática, ao participarem de um grupo de estudos no âmbito do Estágio Curricular Supervisionado, realizado em uma escola pública do interior de Minas Gerais, durante o ano de 2019.

Tendo em vista esse objetivo, discutiremos, inicialmente, aspectos teóricos relacionados ao desenvolvimento da identidade profissional docente na formação inicial de professores de Matemática. Em seguida, apresentaremos os caminhos metodológicos adotados no estudo, as nossas análises realizadas e, por fim, algumas considerações a respeito da temática abordada.

\section{Apontamentos teóricos a respeito da identidade profissional de futuros professores de Matemática}

O conceito de identidade é polissêmico e os aspectos que envolvem a constituição/desenvolvimento da identidade docente são diversificados, o que torna complexa a definição conceitual. No entanto, eles convergem numa definição de identidade como um processo longitudinal e dinâmico de construção e reconstrução do eu comigo e do eu com os outros. Assim, a identidade tem uma dimensão individual e outra social (PELLETIER e MORALES-PERLAZA, 2018).

A identidade não é estática e uniforme, pertence a uma dimensão interpessoal e evolui ao longo do tempo; é influenciada pelos contextos em que os professores trabalham e vivem, pelos conhecimentos e experiências, por valores, sentimentos, emoções, atitudes. A identidade também é múltipla e está associada às dimensões pessoais, situacionais e profissionais, e vai se modificando ao longo do tempo (GARCÍA e GALLEGO-DOMÍNGUEZ, 2018). Um(a) professor(a) com experiência profissional pode, por exemplo, identificar-se pessoalmente como pai/mãe, filho(a) e artesão(ã) e manter, ao mesmo tempo, identidades profissionais como docente de Matemática, como profissional crítico e reflexivo, e como membro da comunidade escolar. Já um professor iniciante (ou futuro professor), com características dessa mesma identidade pessoal, pode não se ver profissionalmente como um docente crítico e reflexivo, no entanto, pode passar a assumir essa identidade quando ganha experiência no campo profissional. 
Na perspectiva de Day (2006), a identidade profissional está intimamente relacionada ao conceito do eu pessoal e profissional do professor, isto é, quem é, sua autoimagem, os significados de si mesmo e do seu trabalho, e os significados que atribui aos outros. A identidade está associada à disciplina escolar que ensina, às relações estabelecidas com seus alunos, aos seus papeis e como os relaciona à sua vida extraescolar. A identidade docente não é construída somente a partir de aspectos técnicos relacionados ao ensino, como gestão da classe e conhecimento do conteúdo, mas também se constitui como o resultado da interação entre as experiências pessoais do professor e seu entorno social, cultural e institucional, e pode sofrer mudança de acordo com o contexto no qual ele está inserido. Para este autor, as emoções desempenham um papel fundamental na construção da identidade e influenciam o modo como 0 professor atua em sala de aula.

Para Cyrino $(2016,2017)$, a construção/desenvolvimento da identidade profissional do professor que ensina Matemática é entendida como um movimento que "se dá tendo vista um conjunto de crenças e concepções interconectadas ao autoconhecimento e aos conhecimentos a respeito de sua profissão, associado à autonomia (vulnerabilidade e sentido de agência) e ao compromisso político" (CYRINO, 2016, p. 168).

Para esta autora, a vulnerabilidade não é entendida como aquela que enfraquece, fragiliza e paralisa, mas sim a que

nos permite suspender por alguns instantes, mais ou menos longos, e mais ou menos frequentes, as nossas certezas e convicções. Aquela que nos faz questionar a nós próprios. Também a vulnerabilidade no sentido de nos expormos aos outros e, como tal, podermos tornar-nos "alvo de crítica, de contestação". (OLIVEIRA e CYRINO, 2011, p. 112).

Nesse sentido, a vulnerabilidade garante ao professor, ou futuro professor, assumir os seus erros e limitações, em possíveis situações de tensões e dilemas da sua (futura) prática docente, de modo que possa superá-los. Para Cyrino (2017, p. 705), para que essa vulnerabilidade não seja vista como fragilidade, "são necessárias ações que, a partir dos espaços instituídos para repensar suas práticas, crenças e concepções, proporcionem aos (futuros) professores oportunidades de operar, mesmo diante da vulnerabilidade, com o sentido de agência".

O professor, ou futuro professor, pratica ou manifesta essa agência quando ele interage "com as estruturas sociais de modo mutuamente constitutivo, exerce influência, faz escolhas, toma decisões que afetam seu trabalho e revelam seu compromisso profissional e ético, por meio de 
suas ideias, motivações, interesses e objetivos" (CYRINO, 2017, p. 706). Para esta autora, no contexto da formação inicial de professores, o sentido de agência deve estar associado diretamente com a construção da identidade profissional.

Como se inicia e se desenvolve a constituição da identidade profissional dos professores?

A identidade do professor vai se constituindo muito antes do ingresso na carreira profissional. O contexto escolar, enquanto aluno, e as relações com a família já trazem características de sua identidade. Esta identidade se desenvolve ao longo da formação inicial, em que o conhecimento profissional é aprofundado de modo a possibilitar o exercício da docência. $E$ é ao longo da licenciatura, especialmente nos momentos em que são vivenciadas as práticas de ensino, que a identidade vai se constituindo (GARCÍA e GALLEGO-DOMÍNGUEZ, 2018). Assim como esses autores, consideramos que as experiências de prática docente nas escolas, proporcionadas aos futuros professores durante o Estágio Curricular Supervisionado, tornam-se um componente imprescindível na formação desses estudantes, pois representam momentos em que os licenciandos vão às escolas e interagem com alunos e professores. Essas experiências da prática pedagógica representam um momento privilegiado para investigar o processo de aprendizagem da docência e de aspectos constitutivos da identidade profissional.

Ao ingressar na Licenciatura em Matemática, o estudante traz consigo um conjunto de crenças e concepções sobre a Matemática, a sua futura profissão, o que significa ser um bom professor de Matemática, que tipo de professor deseja ser, como deverá ensinar, enfim, diversas ações que envolvem a sua futura prática profissional. Essas crenças e concepções influenciam a maneira como o licenciando lida com os conhecimentos necessários ao exercício de sua profissão. Nesse sentido, discutir essas crenças e concepções, ainda na formação, contribui para 0 autoconhecimento profissional do futuro professor, tão necessário para enfrentar as diversas situações profissionais dentro e fora da sala de aula (CYRINO, 2017).

Segundo Kelchtermans (2009), o autoconhecimento envolve cinco componentes interrelacionados: autoimagem, autoestima, motivação para o trabalho, percepção de tarefas e perspectiva futura. Esses componentes são sintetizados no Quadro 1.

Em nosso estudo, entendemos o autoconhecimento enquanto aspecto constitutivo da identidade profissional do futuro professor de Matemática, que é resultante de um processo contínuo de dar sentido a suas próprias experiências (KELCHTERMANS, 2009). 
Quadro 1: Componentes do autoconhecimento do professor

\begin{tabular}{|c|l|}
\hline Componentes & \multicolumn{1}{|c|}{ Descrição } \\
\hline Autoimagem & $\begin{array}{l}\text { Representa como o professor percebe a si mesmo. No entanto, essa } \\
\text { autopercepção é influenciada pelo modo como ele é percebido pelos } \\
\text { outros (alunos, colegas, pais etc.). }\end{array}$ \\
\hline Autoestima & $\begin{array}{l}\text { Intimamente ligado ao componente da autoimagem, a autoestima } \\
\text { refere-se à avaliação que o professor faz de si mesmo ("como eu } \\
\text { estou desenvolvendo o meu trabalho como professor?"). }\end{array}$ \\
\hline Motivação para o trabalho & $\begin{array}{l}\text { Motivos que levam a pessoa a se tornar professor e a permanecer na } \\
\text { profissão. }\end{array}$ \\
\hline Percepção de tarefas & $\begin{array}{l}\text { Componente normativo do autoconhecimento que compreende as } \\
\text { tarefas e deveres do professor para desenvolver um bom trabalho. } \\
\text { Reflete respostas pessoais a questões como: "o que devo fazer para } \\
\text { me tornar um bom professor?", "quais tarefas devo realizar para ter a } \\
\text { sensação de que desenvolvi um bom trabalho?". Envolve escolhas } \\
\text { carregadas de valores e crenças sobre os dever e } \\
\text { responsabilidades morais do professor. }\end{array}$ \\
\hline Perspectiva futura & $\begin{array}{l}\text { Revela as expectativas do professor quanto ao seu futuro profissional } \\
\text { ("como eu me vejo como professor nos próximos anos e como eu me } \\
\text { sinto sobre isso?"). }\end{array}$ \\
\hline
\end{tabular}

Fonte: Kelchtermans (2009)

Como Cyrino (2017), entendemos que o professor, o qual o licenciando se tornará, não depende unicamente dos conhecimentos provenientes de sua formação inicial. 0 processo de constituição da sua identidade profissional está atrelado à sua própria história, às suas crenças e concepções, e às diferentes experiências formativas vivenciadas por ele em contextos da sua futura prática profissional. A identidade é, portanto, um processo complexo e dinâmico, pois

inclui aspectos pessoais, profissionais, intelectuais, morais e políticos dos grupos nos quais os sujeitos estão envolvidos [...]. Consiste não apenas no que os outros pensam ou dizem sobre nós, embora isso também faça parte do nosso modo de viver, mas também de como nos vemos e nossa capacidade de refletir sobre a nossa experiência" (CYRINO, 2016, p. 168).

É um processo complexo pois envolve a família, as experiências como aluno da Educação Básica, a formação inicial recebida - especialmente as primeiras experiências docentes no decorrer do Estágio Curricular Supervisionado -, as reflexões suscitadas pelos professores formadores, as experiências de início da carreira, as relações com seus pares no contexto de trabalho, as políticas públicas e seus desdobramentos, e a visão do outro sobre si e sua atuação profissional (DE PAULA e CYRINO, 2017, 2018). 
Diante do exposto, consideramos que o Estágio Curricular Supervisionado vem a se constituir em um espaço de formação que possibilita ao futuro professor vivenciar situações da prática profissional, nas quais ele tem a oportunidade de ressignificar os saberes construídos ao longo de sua trajetória estudantil, especialmente no curso de Licenciatura em Matemática. 0 compartilhamento de experiências e a vivência de situações no Estágio podem conduzi-lo à reflexão, ao desenvolvimento de saberes e à constituição de sua identidade profissional.

Assim, embasadas pelas ideias expressas anteriormente, desenvolvemos o trabalho de campo da pesquisa. Na próxima seção, apresentaremos a metodologia e os procedimentos metodológicos adotados no estudo.

\section{Metodologia e procedimentos metodológicos}

Na intenção de alcançar o objetivo proposto com este trabalho, optamos por realizar uma pesquisa de natureza qualitativa (YIN, 2016).

O contexto da pesquisa foi o Estágio Curricular Supervisionado I e II da Licenciatura em Matemática do Instituto Federal de Educação, Ciência e Tecnologia de Minas Gerais (IFMG), campus Formiga, realizado no quinto e no sexto período do curso, respectivamente. A carga horária da disciplina de Estágio Supervisionado I é 120 horas: 30 horas teóricas e 90 horas de atividades na escola em turmas dos Anos Finais do Ensino Fundamental. Já no Estágio II, 105 horas são dedicadas às atividades no campo, em classes do Ensino Médio, e 15 horas teóricas. A parte teórica dessas disciplinas é desenvolvida nas dependências do campus Formiga e compreende: orientações para a realização do Estágio na escola, discussões das práticas vivenciadas pelos estagiários, e apresentação de diretrizes para elaboração de relatórios de estágios.

A escolha deste contexto se deu pela atuação da primeira autora como docente do curso de Licenciatura em Matemática no campus Formiga do IFMG, desde 2012, em disciplinas da área de formação pedagógica, relacionadas à Educação Matemática, e, principalmente, como orientadora nos Estágios Curriculares Supervisionados.

Além dos dois licenciandos em Matemática, Kaio e Miguel1 — matriculados nas disciplinas de Estágio Supervisionado I e II -, também participaram da pesquisa os seus supervisores de

\footnotetext{
${ }^{1}$ Nomes fictícios escolhidos pelos próprios estagiários.
} 
Estágio - dois professores do Ensino Fundamental e duas docentes do Ensino Médio.

A pesquisa de campo foi realizada paralelamente aos estágios dos licenciandos, de março a novembro de 2019, em uma escola pública de Formiga (MG), escolhida pelos próprios estagiários. Essa escola situa-se na região central da cidade e funciona em três turnos: Anos Finais do Ensino Fundamental (vespertino), Ensino Médio regular (matutino) e Ensino Médio na modalidade da Educação de Jovens e Adultos (noturno). Apresenta, com bases nos dados dos últimos anos, um dos melhores resultados no Índice de Desenvolvimento da Educação Básica (IDEB) das escolas públicas de Formiga. Também possui sala e recursos para atendimentos de alunos com necessidades educacionais especiais. Ambos os Estágios foram desenvolvidos nessa escola.

Foram realizados 21 encontros com o grupo de estudos, uma vez por semana, com duração de 1 hora cada, sendo 10 no período de março a junho de 2019 e 11 encontros de agosto a novembro do mesmo ano. Os encontros ocorreram na própria escola, em horário extraclasse, sem prejuízo do trabalho cotidiano dos professores e do andamento das atividades acadêmicas dos estagiários. No primeiro semestre, dois professores de Matemática do Ensino Fundamental participaram do grupo, além dos estagiários e da pesquisadora. Esses docentes deixaram de participar das reuniões no segundo semestre por não mais atuarem como supervisores de Estágio dos licenciandos. Assim, na segunda etapa do trabalho, que compreende as atividades do Estágio Supervisionado II, duas professoras do Ensino Médio, também supervisoras de Estágio, passaram a integrar o grupo.

As ações desenvolvidas no e pelo grupo ao longo de 2019 procuraram acompanhar tanto as atividades de estágio propostas no plano das disciplinas - elaborado conjuntamente pelos professores orientadores do campus Formiga do IFMG e pela pesquisadora - quanto o calendário da escola. A dinâmica das reuniões também envolveu a discussão e a problematização das ações docentes realizadas pelos estagiários, como as observações de aula, o planejamento e as regências em sala de aula; as possibilidades de realizar outras atividades previstas no plano por exemplo, as monitorias em horário extra turno -; a análise de episódios de sala de aula com o objetivo de refletir sobre a prática docente; e estudo de temas sugeridos pelos professores supervisores.

A partir de nossas leituras, de experiências com a formação de professores e da premissa básica de que a discussão e tomada de decisão do grupo devem ser coletivas, é que se propôs a 
dinâmica dos encontros. Entendemos que a qualidade dos dados obtidos depende da relação estabelecida entre a pesquisadora, os estagiários e os professores. Essa relação precisa se pautar no respeito mútuo, na confiança entre os participantes do grupo, no diálogo e na reflexão, para que se constitua um espaço coletivo de aprendizagem para todos os envolvidos.

Nesse sentido, cada encontro foi planejado de modo a configurar-se como um espaço coletivo de aprendizagens no qual cada participante pudesse desenvolver-se profissionalmente. Procuramos escutar os professores e os estagiários. Assim, estes foram convidados a ceder narrativas orais (supervisores) e escritas (licenciandos) para que pudéssemos compreender 0 contexto formativo no qual estavam inseridos.

Os instrumentos de produção de dados foram: diário de campo da pesquisadora; gravações em áudio e vídeo de todos os encontros do grupo; uma avaliação e autoavaliação dos encontros pelos participantes - escrita, orientada por questões, realizada ao final do semestre ; uma entrevista narrativa com cada professor supervisor - também realizada ao final do semestre -; e narrativas escritas produzidas pelos licenciandos, com o objetivo de fazer-Ihes contar e refletir sobre as diversas atividades docentes vivenciadas no estágio. Ao todo, os licenciandos produziram sete narrativas, sendo quatro no primeiro semestre e três no segundo. Para este artigo, consideramos nas nossas análises, os dados produzidos por meio da transcrição dos encontros, das narrativas escritas e da avaliação/autoavaliação feita pelos estagiários.

Em nossa pesquisa, as narrativas são tomadas como "narrativas de autoformação", numa perspectiva de autonomização, que é a capacidade de uma pessoa se apropriar do seu próprio poder de formação (PINEAU, 2014). Nesse ponto de vista, as narrativas de autoformação constituem-se um mecanismo formativo para a pessoa, pois possibilita a escrita de si a partir da reflexividade - elemento imprescindível do processo de narração - levando-a a compreender e a tomar consciência de seus saberes.

Para esse autor, os espaços de heteroformação, ecoformação e autoformação são tomados como movimentos formativos produzidos, respectivamente, na relação com os outros, com o meio ambiente e consigo mesmo, num processo de reflexão e autoprodução feito pela pessoa a partir da ação com os outros e com o meio em que vive. Nesse processo, o professor, seja em formação ou em exercício, é um "sujeito autorreferencial" (PINEAU, 2014) ao assumir para si a dinâmica reflexiva da autoformação.

Assim, embasadas nessas ideias e com o intuito de levar os estagiários "a contar a história 
de seu saber-ensinar, através das experiências pessoais e profissionais que foram significativas para eles do ponto de vista da identidade pessoal" (TARDIF, 2014, p. 104), convidamos-lhes a escreverem narrativas de suas experiências vivenciadas nos estágios e no grupo de estudos ao longo ano de 2019.

Ao todo, os licenciandos produziram sete narrativas, sendo quatro no primeiro semestre e três no segundo. O primeiro texto teve como objetivo evocar lembranças, enquanto discentes, na trajetória escolar antes de seu ingresso na graduação, percepções sobre o curso e as disciplinas, e experiências docentes anteriores ao estágio. Em outros dois textos, os estagiários foram convidados a contarem sobre as observações de aula no Ensino Fundamental e Médio. A intenção era que pudessem fazer uma análise reflexiva das aulas de modo a estabelecerem relações com suas próprias aulas. Outras duas narrativas tinham como propósito levar os futuros professores a refletirem sobre a sua atuação profissional, procurando se lembrar dos novos papeis desempenhados e explorados durante as regências, dos recursos didáticos utilizados e se contribuíram ou não para a aprendizagem dos alunos. Ao final de cada semestre, os licenciandos produziram um texto no qual fizeram uma avaliação e autoavaliação dos encontros com o grupo e das atividades propostas para o desenvolvimento dos estágios na escola. Na última narrativa, de modo especial, os estagiários foram convidados a refletir sobre a sua formação e sobre suas as aprendizagens docentes após a conclusão dos Estágios Supervisionados I e II.

Para procedermos com a análise das informações, adotamos a estratégia da triangulação com o objetivo "buscar ao menos três modos de verificar ou corroborar um determinado evento, descrição, ou fato que está sendo relatado por um estudo" (YIN, 2016, p. 94). Procuramos, por meio da triangulação dos dados obtidos - textos resultantes da transcrição dos encontros gravados em áudio/vídeo; narrativas escritas e avaliação/autoavaliação das atividades desenvolvidas nos estágios e no grupo de estudos, produzidas pelos licenciandos - identificar os indícios constitutivos da identidade profissional dos futuros professores. Para isso, realizamos a leitura de todo material, procurando destacar falas importantes que estivessem relacionadas ao objetivo do presente trabalho.

Esse caminho percorrido nos possibilitou analisar os indícios constitutivos da identidade profissional dos futuros professores de Matemática a partir de quatro unidades: trajetória anterior ao estágio; observações de aula; planejamento e regência de aulas; e finalização de etapas. A seguir, apresentaremos as nossas análises. 


\section{Indícios constitutivos da identidade profissional revelados pelos futuros professores de}

\section{Matemática}

Nesta seção, analisamos os indícios constitutivos da identidade profissional docente, manifestados pelos futuros professores de Matemática em suas reflexões sobre as experiências vivenciadas nos Estágios Curriculares Supervisionados I e II, tendo em vista: a trajetória anterior ao estágio; as observações de aula; o planejamento e a regência de aulas; e a finalização de etapas. Esta última abrange as avaliações/autoavaliações feitas pelos estagiários ao término de cada estágio realizado na escola.

\subsection{Trajetória anterior ao estágio}

Convidamos Kaio e Miguel a escreverem uma narrativa de suas trajetórias anteriores ao Estágio Curricular Supervisionado I. Nosso intuito era que rememorassem experiências anteriores ao seu ingresso na Licenciatura em Matemática, que nos contassem sobre o seu processo de formação para se tornarem professores, sobre experiências docentes que antecederam o primeiro Estágio e suas expectativas quanto a ele.

Miguel tem 22 anos de idade, é natural de Ouro Preto e estudante do quinto período do curso de Licenciatura em Matemática do IFMG, campus Formiga. É bolsista do Programa Institucional de Bolsas de Iniciação à Docência (PIBID) e atua em atividades voltadas aos cursos técnicos integrados ao Ensino Médio da própria instituição em que faz a sua graduação. Já participou de eventos da Educação Matemática realizados em outras instituições e de jornadas culturais oferecidas pelo IFMG.

Em sua primeira narrativa, Miguel nos contou sobre a sua relação com a Matemática e com os professores dessa disciplina durante a sua formação escolar, suas expectativas quanto ao curso de graduação e quanto ao primeiro Estágio.

Minha relação com a matemática, vem desde o ensino fundamental, pois é a matéria que sempre tive facilidade e gosto para aprender. Sendo assim, desde os anos iniciais de minha formação, meu pai estudava essa disciplina comigo, me incentivando a seguir na área das exatas. Outro fator que contribuiu para que eu seguisse esse caminho, foi o meu relacionamento com os meus antigos professores de matemática, uma vez que eu gostava muito de conversar com eles a respeito dessa disciplina. Dessa forma, a cada ano que ia se passando, eu aprendia novos conteúdos e conseguia relacionar a matemática em meu dia a dia.

Diferentemente de quando eu era aluno, perceber as atitudes do professor e suas atribuições dentro do ambiente escolar, me levaram a crer que não será tarefa fácil 
entrar em uma sala de aula para lecionar, já que as dificuldades são muitas. No entanto, é preciso que um estudante de licenciatura tenha a autoconfiança de que cada dia de trabalho será melhor do que o anterior. (Narrativa de Miguel, 08/06/2019).

A narrativa de Miguel revela indícios constitutivos de sua identidade profissional docente. Um deles é a motivação para o trabalho, um dos componentes do autoconhecimento (KELCHTERMANS, 2009), ao contar que o incentivo dado pelo seu pai e bom relacionamento com seus professores de Matemática da Educação Básica, contribuíram para sua escolha profissional. O contexto escolar anterior à graduação e as relações com a família já trazem características de sua identidade (GARCÍA e GALLEGO-DOMÍNGUEZ, 2018) e de um movimento que inicia antes de seu ingresso no curso e que ganha forma na formação inicial (CYRINO, 2017).

Outro aspecto relacionado à identidade profissional de Miguel diz respeito à transição de aluno a professor (PIMENTA, 2005; GARCÍA e GALLEGO-DOMÍNGUEZ, 2018; PELLETIER e MORALES-PERLAZA, 2018). No segundo excerto de sua narrativa, podemos observar que as experiências vivenciadas pelo estagiário o levaram a refletir sobre a sua futura profissão e colaboraram com o processo de constituição da sua identidade profissional que

\footnotetext{
se constitui durante esse período, quando o aluno passa de um lado da classe para 0 outro, de estudante a professor, tendo que procurar uma construção forte de sua identidade para evitar cair em tensões causadas pela mudança contextual, das relações institucionais, etc., enfim, seu novo espaço profissional. (GARCía e GALLEGO-DOMÍNGUEZ, 2018, p. 55-56).
}

Kaio é colega de Miguel, tem 21 anos de idade e reside com sua família em Formiga. Em 2016, aos 18 anos de idade, concluiu o Ensino Médio e no ano seguinte ingressou no ensino superior. Ele nos contou que, desde dezembro de 2017, é bolsista do PIBID, e desenvolve atividades como monitorias, cursinho preparatório para o Exame Nacional do Ensino Médio (ENEM), simulados para vestibulares, cursos de nivelamento e gincanas para alunos dos cursos técnicos integrados ao Ensino Médio do campus Formiga do IFMG. Também nos informou que foi monitor da disciplina de "Introdução à Álgebra" ofertada para o primeiro período do curso de Licenciatura em Matemática.

Com relação às expectativas para o seu primeiro Estágio, Kaio trouxe algumas inquietações em sua narrativa, como o desafio de lidar com o tempo e o conteúdo a ser ensinado, o desinteresse e a falta de motivação dos alunos, e o uso de teorias de aprendizagem pelos professores. Em suas palavras: 
Como lidar com todo o conteúdo extenso e detalhado de Matemática em um período de tempo tão curto, como aulas de 50 minutos, de forma que o aluno consiga realmente aprender?

[...] como lidar com o desinteresse e desmotivação de grande parte dos alunos do Ensino Fundamental, causado as vezes pela própria idade?

Os professores utilizam de alguma teoria/estratégia de aprendizagem estudadas durante a graduação, seja de forma direta ou indireta, para melhor ministrarem suas aulas? (Narrativa de Kaio, 19/06/2019).

Também identificamos aspectos da identidade, enquanto futuro professor, manifestados por Kaio. A última questão, trazida por ele em sua narrativa, revela indícios de uma possível concepção, que faz parte de sua identidade profissional (CYRINO, 2016, 2017), de que o uso de teorias/estratégias de aprendizagem é um modo de melhorar a qualidade de suas aulas e, consequentemente, a aprendizagem de seus alunos. Os questionamentos de Kaio também trazem indicativos de ações que ele poderia implementar no Estágio Curricular Supervisionado, no sentido de desenvolver um bom trabalho enquanto professor. Tal elemento se relaciona à percepção de tarefas, um dos componentes do autoconhecimento (KELCHTERMANS, 2009).

\subsection{Observação de aulas}

Os estagiários foram convidados a escreverem duas narrativas sobre as observações de aula, uma no Ensino Fundamental e outra, no Médio. A nossa intenção era que pudessem fazer uma análise reflexiva das aulas observadas de modo a estabelecerem relações com suas próprias aulas.

A observação realizada pautou-se na perspectiva investigativa da realidade (BARREIRO e GEBRAN, 2015) e serviram tanto para compreender a prática pedagógica do professor supervisor, quanto para orientar as próprias ações do licenciando como futuro professor, ao facilitar a percepção da realidade a partir de um olhar crítico e investigativo.

Ao narrar as observações de aula, Kaio e Miguel realizaram análises reflexivas sobre as suas próprias aulas (CARVALHO, 2017). Procuraram identificar aspectos no processo de ensino e aprendizagem da Matemática - abordagem do conteúdo ministrado pelo professor supervisor, relação com os alunos, dificuldades dos discentes na aprendizagem do conteúdo, avaliação etc. - e levantar possíveis questões sobre os mesmos, afim de obter respostas que pudessem contribuir para melhorar a sua prática docente. A seguir, apresentamos alguns excertos em que os estagiários realizaram essas análises. 
Fazendo uma reflexão, cada turma requer uma metodologia diferente, já que a mesma aula que o professor leciona para uma turma, não servirá para outra classe, mesmo que o conteúdo seja igual. Particularmente, eu prefiro as aulas expositivas e dialogadas, pois sinto que é a melhor forma que eu aprendo os conteúdos de matemática. No entanto, quando eu estiver lecionando, não será a única metodologia que vou utilizar, uma vez que as turmas serão diferentes e 0 jeito de cada aluno aprender, também. A partir das observações que fiz nas turmas do sétimo ano, vi que tinha alunos que aprendiam e gostavam do estilo de aula de meu supervisor, e outros que não conseguiam fixar o conteúdo. [...] Enquanto professor, vou sempre adequar a turma que eu estiver lecionando, procurando sempre inovar em minhas aulas. (Narrativa de Miguel, 19/06/2019).

Considero o período de observação de aulas bastante significativo para meu processo de formação, pois possibilita a visão de um ponto de vista ainda não vivenciado, podendo observar no mesmo campo a atuação do professor ao ensinar o conteúdo e ao lidar com o comportamento dos alunos, bem como as reações dos mesmos à atitude do professor. (Narrativa de Kaio, 19/06/2019).

Logo quando comecei a fazer as observações de aulas, já vi a "correria" em ensinar os conteúdos aos alunos, visto que a ementa de matemática para o ensino fundamental é muito extensa. Além disso, esses conteúdos que os alunos aprendem, é base para a matemática do ensino médio e superior. Assim, trabalhar os conceitos de maneira rápida, é prejudicial para o aprendizado dos alunos. (Narrativa de Miguel, 12/07/2019)

[...] acho positiva a forma como a professora trabalha o conteúdo, sempre chamando a atenção para o que ela está expondo, pedindo respostas e dialogando com os discentes dando espaço para que consigam tirar suas dúvidas e aprender com o erro e com o diálogo entre os colegas e o professor. Acho importante o tipo de relação que a docente mantém com seus alunos, uma relação amigável e respeitosa. No entanto creio que ela poderia buscar outras metodologias de ensino alternativas como: jogos, oficinas, vídeos, o uso de recursos tecnológicos [...] de forma a despertar um maior interesse nos alunos [...]. (Narrativa de Kaio, 19/06/2019).

A narrativa de Miguel sobre a observação de aulas trouxe indícios da constituição de sua identidade como futuro professor. Um deles se relaciona à intenção de incorporar ou não aspectos da prática pedagógica observadas em outros professores, um elemento associado à identidade profissional docente (TEIXERA e CYRINO, 2014), ao se posicionar sobre o estilo de aula que prefere. Esse posicionamento do estagiário também indica uma possível crença de que os alunos aprendem melhor os conteúdos matemáticos por meio de aulas expositivas e dialogadas. As crenças também revelam aspectos da identidade profissional docente, conforme estudos de Cyrino $(2016,2017)$. Outra narrativa revela características relacionadas ao compromisso moral, outro aspecto inerente à identidade profissional (RODRIGUES e CYRINO, 2020). Ao considerar que os conteúdos vistos no Ensino Fundamental servem de base para o Ensino Médio e o Ensino Superior e, que por isso, abordá-los rapidamente seja prejudicial ao aluno, o estagiário traz reflexões carregadas de propósitos morais - aquilo que o professor acredita ser correto ou não, e ações que mostram a sua preocupação com aquilo que considera melhor para os alunos.

Ao fazer uma observação analítica das aulas, Kaio mostra direcionar o seu olhar sobre 0 
outro - professor, aluno, escola, currículo, prática pedagógica - e começa a construir a sua identidade como professor (PIMENTA, 2005). De acordo com García e Gallego-Domínguez (2018), a identidade profissional se constitui durante esse período de transição de estudante a professor, quando o licenciando vai de um lado da classe para o outro. $O$ último excerto da narrativa também revela dois aspectos importantes da aprendizagem da docência relacionados ao desenvolvimento da identidade profissional: necessidade de o professor conhecer estratégias metodológicas que possibilitem aulas diferentes das aulas tradicionais, e reconhecer a importância da relação professor-aluno para o processo de ensino e aprendizagem da Matemática (TEIXEIRA e CYRINO, 2014).

\subsection{Planejamento e regência de aulas}

Dentre as diversas ações realizadas pelos futuros professores de Matemática durante os Estágios Supervisionados I e II, as regências se configuraram como possibilidades de desenvolvimento de práticas pedagógicas dos estagiários ao assumirem turmas de alunos no Ensino Fundamental e no Ensino Médio. Segundo Teixeira e Cyrino (2015a), esta ação pode ser considerada como uma das mais importantes do Estágio, assim como destacado no documento da Sociedade Brasileira de Educação Matemática (SBEM, 2003, p. 24): "atividades que culminam o Estágio Supervisionado são as de regência em salas de aula de Matemática nos diferentes níveis e modalidades da educação básica em que o futuro professor poderá atuar".

Antes da realização das regências, Kaio e Miguel planejaram as aulas em parceria com os seus supervisores e a pesquisadora. Os planos de aula foram discutidos individualmente no grupo de estudos, ou seja, reservado um tempo das discussões para cada estagiário. Esses momentos se constituíram em grandes aprendizagens da docência, por possibilitar que as aulas fossem analisadas pelos próprios professores das turmas nas quais as regências seriam desenvolvidas. Após a realização das aulas, tanto no Ensino Fundamental quanto no Médio, as regências também foram discutidas no grupo. Nosso intuito era que os professores supervisores pudessem analisar a atuação docente dos estagiários, e que os licenciandos avaliassem a própria prática depois da realização das regências.

Em suas primeiras experiências docentes no Ensino Fundamental, os estagiários valeramse de metodologias de ensino distintas das observadas nas aulas de seus professores supervisores. De acordo com Carvalho (2017), os materiais didáticos utilizados pelo futuro 
professor de Matemática durante suas atividades do estágio e o contexto profissional que a escola oferece podem contribuir para que o licenciando se torne um agente de mudança em potencial. $A$ seguir, apresentamos excertos de suas narrativas.

\begin{abstract}
Inicialmente, minha ansiedade atrapalhou um pouco, já que era minha primeira regência e tive a dificuldade em controlar meu nervosismo. Aos poucos, essa ansiedade foi passando e eu ficava mais tranquilo. [...] Na turma $7^{\circ} \mathrm{C}$, foi um desafio muito grande, pois a sala é muito inquieta, sendo a turma mais difícil em aplicar a atividade. [...] Como foi minha primeira regência, de início não mudaria muita coisa, pois tirando os problemas que enfrentei, gostei da realização da atividade, apesar da quantidade de alunos dentro da sala de aula. Sendo assim, pensando nessa mesma atividade em uma outra oportunidade, o jogo Matix nos permite trabalhar outros conceitos matemáticos, como tabuada, potenciação, radiciação e expressões algébricas, por exemplo. Como proposta futura, trabalhar esses conteúdos com todos esses alunos, mas com grupos menores, seria muito válido para eles, além de ser uma aula diferenciada. (Narrativa de Miguel, 08/07/2019).

Trabalhar com alunos dessa idade foi uma experiência nova, onde encontrei certa dificuldade em lidar com a ansiedade dos mesmos. Quanto a minha atuação, creio que poderia fazer diferente ao me impor mais quando a turma perdeu um pouco da atenção e quanto à disposição das peças no quadro [se referindo às peças do Algeplan], que me tomaram bastante espaço para resolver os exemplos e corrigir os exercícios. [...] Pode-se perceber na prática que o tempo muitas vezes não permite a conclusão de uma aula elaborada, exigindo a todo momento que o professor se reorganize e busque caminhos para superar esse obstáculo e fazer com que os alunos recebam o conteúdo da melhor forma possível. (Narrativa de Kaio, 13/08/2019).
\end{abstract}

Ao produzirem narrativas sobre suas regências, Miguel e Kaio refletiram sobre a sua atuação docente após a ação, o que possibilitou aos futuros professores tomar certo distanciamento do objeto de estudo, a prática durante a ação, para poder analisá-lo (PELLETIER e MORALES-PERLAZA, 2018). Ao se colocaram no lugar dos professores, tiveram a oportunidade de desempenhar e explorar novos papeis como docentes, além de testar inovações curriculares, contribuindo para o seu desenvolvimento profissional (TEIXEIRA e CYRINO, 2015a).

As reflexões dos futuros professores sobre o planejamento e a regência de aulas no primeiro estágio evidenciaram algumas ações que caracterizam a emoção, aspecto inerente ao movimento de constituição da identidade profissional (DAY, 2006; RODRIGUES e CYRINO, 2020). Isso pode ser observado nos excertos de suas narrativas ao compartilharem experiências não necessariamente positivas - dificuldades em lidar com a indisciplina, com a ansiedade dos alunos, com o tempo e turmas cheias -, e informações sobre o nervosismo (Miguel). Também trouxeram reflexões que indicam a autoestima e a percepção de tarefas, componentes do autoconhecimento (KELCHTERMANS, 2009), um aspecto da identidade profissional. Ao fazer uma autoavaliação da sua atuação docente, Kaio reconhece a necessidade de se impor na sala 
de aula, de melhorar a organização do quadro, de replanejar a aula — devido ao tempo — de modo que os alunos aprendam. Miguel reflete sobre os conteúdos abordados no desenvolvimento do jogo e a dinâmica adotada na organização da sala, e projeta ações futuras.

Miguel e Kaio planejaram aulas para turmas de primeiro e terceiro ano do Ensino Médio, respectivamente. $O$ plano de aula desenvolvido por Miguel envolveu situações-problema sobre gráficos de funções polinomiais do $1^{\circ}$ e $2^{\circ}$ graus, tema sugerido pela professora supervisora. Para desenvolvê-lo em sala de aula, o estagiário utilizou uma folha de atividades, que foi entregue aos alunos, e planejou o uso do datashow para projetar o gráfico de algumas funções que havia construído no GeoGebra. O tema das aulas planejadas por Kaio foi Projeção Ortogonal, também sugerido pela sua professora supervisora. O estagiário usou como recursos didáticos: uma folha de atividades contendo questões do Exame Nacional do Ensino Médio (ENEM), sólidos geométricos de acrílico escuro, uma lanterna para projetar as sombras, e o datashow para mostrar as animações, que ele mesmo fez, de algumas projeções.

Os licenciandos valeram-se de outros materiais didáticos nas regências realizadas no Ensino Médio, e mostraram mais confiança enquanto futuros professores. A seguir, apresentamos excertos de falas dos estagiários e das professoras supervisoras ${ }^{2}$ ao fazerem as análises das aulas no grupo de estudos.

De certo modo, saiu como eu esperava. Eu queria trabalhar mais no quadro, resolver alguns exercícios no quadro. [...] Não deu para resolver todos os exercícios. [...] Eu devia ter organizado melhor essa questão do tempo. [...] Eu senti que eu dei muito tempo pra eles resolverem as questões. Mas, assim, num exercício ou outro, surgem muitas dúvidas e tudo. Então, assim, a gente gastou mais tempo em alguns exercícios. Mas aquela questão de mexer no quadro, escrever no quadro pra eles e tudo, assim, foi bem legal. Eu questionei mais os alunos, em vista da minha primeira regência. [...] E me senti mais confiante de trabalhar esse tipo de regência do que na anterior, que eu trabalhei o jogo. Eu senti mais confiança de trabalhar esses exercícios. (Miguel, $5^{\circ}$ encontro, ECS II, 30/09/2019).

Primeiro, foi a dificuldade de encontrar algo prático, algo diferente quanto à projeção [...]. Eu encontrei muito em disciplina de desenho técnico, de curso técnico, do SENAI, essas coisas. [...] Então, eu tinha aquele desenho pronto, colorido. Eu disse: "Não, mas, se eu mostrar pronto, já está com as respostas, talvez nem entendam [referindose aos alunos]". Aí, eu desconstruí todo ele, redesenhei no Corel e exportei imagem por imagem. $\mathrm{O}$ plano, a figura e as três sombras. [...] Acredito que deu bastante certo no slide por conseguir mostrar o plano, o ponto, como que surgia a projeção. Acho que o que não saiu como tão esperado foi a parte da resolução, porque... talvez, por falta de interesse dos meninos com a resolução. Talvez, achei que eu teria que dar mais assistência na hora de resolver. Alguns tentaram resolver e me chamaram, outros não tentaram tanto. [...] Então, acho que, dentro do planejamento, saiu como esperado.

\footnotetext{
2 No segundo semestre de 2019, Cristina foi supervisora de estágio de Kaio e, Vitória, supervisora de Miguel. Os nomes das professoras também são fictícios e foram escolhidas por elas.
} 
(Kaio, $5^{\circ}$ encontro, ECS II, 30/09/2019).

Eu fiquei insatisfeito por causa do seguinte... Assim, se eu fosse o professor da turma e tudo, eu teria a chance de continuar na próxima aula. [...] E procuraria atender, tirar as dúvidas... (Miguel, $5^{\circ}$ encontro, ECS II, 30/09/2019).

Então, foi uma dificuldade que eu encontrei em que eu, até então, não tinha passado [trabalhar com tema sugerido pela professora supervisora]. [...] Não envolvia nenhum cálculo, nenhuma conta, nenhuma regra. Somente uma visualização. Fazer com que eles [os alunos], com as minhas palavras, eles compreendessem o que era pra ser visualizado. Foi uma coisa nova, assim, que eu não tinha passado até então. Um desafio. (Kaio, $5^{\circ}$ encontro, ECS II, 30/09/2019).

Você explicou direitinho. Única coisa que eu te alerto é quanto à disciplina. Você não ficar explicando coisas com eles conversando. [...] No princípio, você já fala: [...] "Olha, para haver uma boa aprendizagem, vocês precisam ficar atentos. Eu estou aqui para tirar todas as dúvidas, eu estou para ensinar, mas eu preciso da atenção de todos vocês. Se não, vocês não vão entender". A gente passa por isso até hoje. (Vitória, ECS II, $5^{\circ}$ encontro, 30/09/2019).

Me chamou atenção que eu gostei, Kaio, é a sua voz. É uma voz forte. [...] Então, eu acho que é um ponto positivo. Você fala alto e pra fora. [...] Agora, assim, eu achei a sua aula boa, achei aquele negócio que você fez... [referindo-se ao recurso utilizado pelo estagiário para facilitar a compreensão da visualização] eu achei muito bom aquele lá pra visualizar. E, agora, eu fiquei até com pena, que eu te joguei numa fria, porque eu que sugeri esse assunto. [...] Eu acho que você pode falar a palavra simples mesmo. Usar um linguajar correto, mas simples. Quanto mais simples, melhor. (Cristina, ECS II, $5^{\circ}$ encontro, 30/09/2019).

As falas de ambos os estagiários trazem elementos associados ao autoconhecimento (KELCHTERMANS, 2009), um aspecto do movimento de constituição da identidade profissional. Ao fazerem uma autoavaliação de suas ações docentes, os futuros professores: i) mostraram interesse pela aprendizagem dos alunos, ao procurarem esclarecer as dúvidas e dispor de recursos para facilitar a visualização de gráficos e imagens tridimensionais; ii) anteciparam possíveis dificuldades dos alunos ao planejarem as aulas; iii) repensaram sobre suas atuações após as aulas. Tais ações revelam indícios de como eles se veem enquanto professores (autoimagem), como estão desenvolvendo o seu trabalho (autoestima), como poderiam fazer para se tornarem bons professores e desenvolverem melhor suas atribuições (percepção de tarefas). Também vimos que as emoções desempenharam um papel fundamental no processo de constituição da identidade desses licenciandos, mais explicitamente nas falas de Miguel, e influenciaram o modo como eles atuaram em sala de aula (DAY, 2006).

Compartilhar experiências não necessariamente positivas sobre dificuldades que tiveram nas regências, imaginar situações que poderiam acontecer em sala de aula, reconhecer suas limitações e a necessidade de readaptação do planejamento, também são ações dos estagiários que revelam aspectos relacionados à emoção e ao compromisso moral (RODRIGUES e CYRINO, 2020). 
Além de estarem suscetíveis às críticas de seus professores supervisores, os estagiários também vivenciaram outras experiências de vulnerabilidade. No caso de Kaio, o tema da aula sugerido por Cristina tornou-se um desafio, pois ele não tinha trabalhado o assunto em experiências anteriores, e a temática envolvia a visualização e o uso de vocabulário que poderiam dificultar a aprendizagem dos alunos. Então, enquanto futuro professor, Kaio agiu frente a essa situação de vulnerabilidade (sentido de agência) e buscou alternativas para abordar o conteúdo de maneira que fosse mais significativo para os alunos, evidenciando autonomia. Esse é um aspecto relacionado à identidade profissional associado à vulnerabilidade e ao sentido de agência (CYRINO, 2017).

\subsection{Finalização de etapas}

Ao final de cada etapa das atividades do grupo de estudos, que corresponde ao término de cada Estágio desenvolvido pelos licenciandos na escola, foi realizada uma avaliação/autoavaliação. Nossa intenção era que os participantes avaliassem os encontros e se autoavaliassem quanto à motivação, à participação e ao envolvimento com o grupo.

Recortamos um trecho da narrativa de Miguel e das falas de Kaio que evidenciam aspectos do movimento de identidade profissional docente, suscitados pelas atividades de Estágio Curricular Supervisionado e pelo grupo de estudos.

Nesse período de estágio, tive a oportunidade de ter mais um contato com minha futura profissão. Repetir essa experiência foi muito satisfatória, pois vivenciei novamente 0 que se passa no dia a dia do ambiente escolar, já que pude observar as dificuldades que o profissional da educação enfrenta no cotidiano. Saber lidar com turmas cheias e inquietas, não é uma tarefa fácil, uma vez que demanda postura do professor para que ele conquiste a confiança e à atenção dos alunos. Finalizando, entre todas as dificuldades que um profissional da educação enfrenta, é muito prazeroso quando ensinamos um conteúdo a um jovem e ele demonstra alegria por ter aprendido. No entanto, é difícil não considerar as precariedades da educação no Brasil, porém o filósofo Mario Sergio Cortella, diz: "... faça o melhor, não o melhor do mundo, mas o seu melhor, na condição que você tem, enquanto você não tem condições melhores para fazer melhor ainda". Dessa forma, levarei essa frase comigo, para que eu possa me dedicar ao máximo em uma sala de aula. (Narrativa de Miguel, 28/11/2019).

Eu acho que o que eu posso levar como experiência que vai me agregar e eu gostei muito, tanto no primeiro quanto nesse [se referindo aos Estágios Supervisionados I e II], foi a parte de discussão pós-regência. Então, assim, eu penso: "E se não tivesse 0 grupo? Eu teria aquele retorno que a Cristina me deu, que você me deu? [referindo à pesquisadora] É... dicas que a gente recebe". Então, são palavras, são frases específicas... É sobre o que eu fiz, sobre a minha prática. Que a gente está começando. [...] Então, acho que essas avaliações, os comentários, dicas, conselhos é o que eu posso levar... Então... pra mudar, pra poder melhorar. [...] E também a ideia 
de não ser só eu e minha supervisora, mas sim tem o Miguel e a supervisora dele. [...] A gente acompanhou a elaboração do plano do Miguel que era para o primeiro ano. Então, se eu tiver oportunidade de trabalhar com primeiro ano, então, já tem alguém que tem experiência, já vi como que ele trabalhou. (Kaio, $11^{\circ}$ encontro, ECS II, 27/11/2019).

As reflexões sobre as experiências vivenciadas nos estágios, suscitadas tanto pelas narrativas quanto pelas discussões do grupo de estudos, revelaram indícios constitutivos da identidade profissional dos futuros professores de Matemática. Tais indícios estão associados a aspectos como: passar a se perceber como professor e não como aluno (PIMENTA, 2005; GARCÍA e GALLEGO-DOMÍNGUEZ, 2018; PELLETIER e MORALES-PERLAZA, 2018); pensar sobre suas escolhas pela carreira e anseios profissionais (GARCÍA e GALLEGO-DOMÍNGUEZ, 2018); pensar sobre suas tarefas enquanto professor e sobre suas perspectivas quanto ao futuro profissional (KELCHTERMANS, 2009); desenvolver autonomia para poder agir em situações que acredita que seja melhor; e refletir sobre o seu compromisso político frente à futura profissão (CYRINO, 2016, 2017; RODRIGUES e CYRINO, 2020).

\section{Considerações finais}

Neste estudo, buscamos analisar os indícios constitutivos da identidade profissional de futuros professores de Matemática, ao participarem de um grupo de estudos no âmbito do Estágio Curricular Supervisionado, desenvolvido numa escola pública do interior de Minas Gerais ao longo de 2019. Para alcançar nosso objetivo, realizamos uma pesquisa qualitativa e tomamos como fonte de produção e de análise dos dados: as narrativas escritas dos estagiários, os excertos de falas advindas da transcrição dos encontros do grupo e a avaliação/autoavaliação do processo vivido pelos estagiários. As reflexões sobre as experiências formativas, suscitadas pelas narrativas e pelas discussões no grupo, possibilitaram revelar aspectos do movimento de identidade profissional dos estagiários.

As experiências vivenciadas por Miguel e Kaio durante o Estágio Supervisionado proporcionaram a mobilização de um olhar voltado essencialmente para si (visão de alunos), para um olhar sobre o outro (professor, aluno, escola, currículo, prática pedagógica). As interações com os alunos, com os professores supervisores, com seus pares, com a pesquisadora e com a prática pedagógica, possibilitaram refletir sobre a própria prática enquanto professores e a construir a sua identidade profissional. Nesse processo, vimos que as emoções também contribuíram para 0 movimento da identidade docente. 
Ao se preocuparem com a aprendizagem e a desmotivação dos alunos, ao refletirem sobre metodologias de ensino, sobre uso do quadro e dinâmicas de organização da sala de aula, e sobre como lidar com a indisciplina, Kaio e Miguel revelaram aspectos de sua identidade profissional enquanto futuros professores. Percebemos esses indícios especialmente em suas narrativas, quando indicaram um estilo preferido de aula - expositiva ou com metodologias de ensino alternativas -, a intenção de incorporar ou não elementos da prática pedagógica observada, a necessidade de conhecer diferentes estratégias de ensino como forma de motivar os alunos, e 0 reconhecer a importância da relação entre professor e alunos.

As atividades de Estágio Curricular Supervisionado e, particularmente, o grupo de estudos constituído em nossa pesquisa, contribuiu para que os futuros professores de Matemática revelassem aspectos relacionados a como se veem como professores (autoimagem). Isso permitiu que os licenciandos se avaliassem em suas ações docentes (autoestima). As experiências formativas nos estágios também os levaram a pensar sobre suas escolhas e anseios profissionais (motivação para o trabalho); a refletir sobre o que significa ser um bom professor e, com isso, pensar a respeito de suas ações docentes (percepção de tarefas); e por fim, a pensar sobre suas expectativas enquanto futuro professor (perspectiva futura). Esses aspectos estão associados ao autoconhecimento.

O estudo também mostrou elementos relacionados à autonomia dos futuros professores, outro aspecto do movimento de identidade profissional. Em experiências de vulnerabilidade, como por exemplo, estar suscetível às críticas dos professores supervisores, os estagiários foram levados a refletir sobre como agir em situações inesperadas de modo que possam contribuir para a aprendizagem dos alunos. Também identificamos um compromisso político dos estagiários com a futura profissão.

O trabalho também evidenciou potencialidades das narrativas na constituição da identidade profissional docente. Ao produzirem escritas reflexivas de si e do seu processo de formação no Estágio, a partir da interação com os outros (os professores, os alunos, a pesquisadora e os colegas), com a escola e consigo mesmo, os licenciandos se apropriaram do seu próprio poder de formação, tomaram consciência de seus saberes e começaram a se identificar como professores. As narrativas tornaram-se, portanto, importantes fontes de produção de informações e possibilitaram um melhor entendimento dos aspectos da identidade profissional dos futuros professores de Matemática. 
Consideramos que o processo formativo, vivenciado pelos futuros professores de Matemática nos estágios e nos encontros com o grupo de estudos, e as reflexões suscitadas pelas narrativas, contribuíram para o movimento de constituição da identidade profissional docente. 0 nosso estudo também mostrou a importância dos cursos de Licenciatura em Matemática que, além de oferecer ao futuro professor os conhecimentos profissionais, também deve contribuir para 0 processo de constituição da identidade profissional dos licenciandos, a fim de formar profissionais que tenham responsabilidade, autonomia e ética, e que sejam capazes de refletir sobre a sua (futura) profissão.

Por fim, nosso estudo procurou analisar os indícios constitutivos da identidade profissional de futuros professores de Matemática num contexto específico. A pesquisa se realizou no âmbito do Estágio Curricular Supervisionado de determinado curso de Licenciatura em Matemática. 0 grupo de estudos foi formado por estudantes desse curso, que trouxeram experiências anteriores ao Estágio e ao seu ingresso na graduação; por professores de Matemática com tempo e experiências profissionais distintas; e pela pesquisadora que carrega consigo a sua identidade pessoal e profissional. Os encontros ocorreram numa escola pública, com suas especificidades e desafios. Além desses espaços formativos (os estágios e o grupo de estudos), os aspectos da identidade profissional foram analisados à luz dos referenciais teóricos por nós assumidos. Evidentemente, outros elementos do movimento de identidade profissional de futuros professores de Matemática seriam identificados caso a pesquisa fosse desenvolvida em contextos diferentes, e as análises feitas a partir de outras perspectivas teóricas. Isso sugere possibilidades de investigações futuras na formação inicial de professores em contextos e espaços não pesquisados neste trabalho.

\section{Agradecimentos}

A primeira autora agradece à Coordenação de Aperfeiçoamento de Pessoal de Nível Superior (CAPES) pelo apoio financeiro dado ao convênio firmado entre a Universidade Cruzeiro do Sul (UNICSUL) e o IFMG, e ao campus Formiga do IFMG pelo afastamento concedido para qualificação. 


\section{Referências}

BARREIRO, Iraíde Marques de Freitas; GEBRAN, Raimunda Abou. Prática de Ensino e Estágio Supervisionado na formação de professores. 2. ed. São Paulo: Avercamp, 2015.

CARNEIRO, Reginaldo Fernando. Narrativas no Estágio Supervisionado em Matemática como uma possibilidade para discussão da profissão docente. In: REUNIÃO ANUAL DA ASSOCIAÇÃO NACIONAL DE PÓS-GRADUAÇÃO E PESQUISA EM EDUCAÇÃO, 37, 2015, Florianópolis. Anais da $37^{\text {a }}$ REUNIÃO ANUAL DA ANPEd. Florianópolis: ANPEd, 2015, p. 1-17.

CARVALHO, Anna Maria Pessoa. Os estágios nos cursos de licenciatura. São Paulo: Cengage Learning, 2017.

CYRINO, Márcia Cristina de Costa Trindade. Formação de professores que ensinam Matemática em comunidades de prática. In: CONGRESSO IBEROAMERICANO DE EDUCAÇÃO MATEMÁTICA, 7, 2013, Montevideu. Actas del VII CIBEM. Montevideu: SEMUR, 2013, p. 51995206.

CYRINO, Márcia Cristina de Costa Trindade. Identidade profissional de (futuros) professores que ensinam Matemática. Perspectivas da Educação Matemática, Campo Grande, v. 10, n. 24, p. 699712, dez. 2017.

CYRINO, Márcia Cristina de Costa Trindade. Mathematics teachers' professional identity development in communities of practice: reifications of proportional reasoning teaching. Bolema, Rio Claro, v. 30, n. 54, p. 165-187, jan./abr. 2016.

DAY, Christopher. Pasión por enseñar: la identidade personal y professional del docente y sus valores. Madrid: Narcea, 2006.

DE PAULA, Enio Freire; CYRINO, Márcia Cristina de Costa Trindade. Identidade profissional de professores que ensinam Matemática: panorama de pesquisas brasileiras entre 2001-2012. Zetetiké, Campinas, SP, v. 25, n. 1, p. 27-45, jan./abr. 2017.

DE PAULA, Enio Freire; CYRINO, Márcia Cristina de Costa Trindade. Perspectivas de identidade profissional de professores que ensinam Matemática presentes em dissertações e teses brasileiras. In: CYRINO, Márcia Cristina de Costa Trindade. (Org.). Temáticas emergentes de pesquisas sobre a formação de professores que ensinam Matemática: desafios e perspectivas. Brasília: SBEM, 2018, p. 125-153.

GARCÍA, Carlos Marcelo; GALLEGO-DOMÍNGUEZ, Carmen. ¿Quién soy yo como maestro? Construcción de la identidad profesional em docentes principiantes. In: CANTÓN MAYO, Isabel, TARDIF, Maurice. (Coord.). Identidad profesional docente. Madrid: Narcea Ediciones, 2018, p. 4556.

KELCHTERMANS, Geert. Who I am in how I teach is the message: selfunderstanding, vulnerability and reflection. Teachers and Teaching: theory and practice. v. 15, n 2, p. 257-272, 2009.

LOPES, Celi Espasandin; TRALDI JR., Armando; FERREIRA, Ana Cristina. Perspectivas para o estágio como espaço para a aprendizagem docente. In: LOPES, Celi Espasandin; TRALDI JR., Armando; FERREIRA, Ana Cristina. (Org.). O Estágio na formação inicial do professor que ensina 
matemática. Campinas, SP: Mercado de Letras, 2015, p. 173-178.

OLIVEIRA, Hélia Margarida; CYRINO, Márcia Cristina de Costa Trindade. A formação inicial de professores de Matemática em Portugal e no Brasil: narrativas de vulnerabilidade e agência. Interacções, Santarém, v. 7, n. 18, p. 104-130, 2011.

PELLETIER, France; MORALES-PERLAZA, Adriana. Saber e identidad en la profesión docente: de la identidade de estudiante a la de docente principiante. In: CANTÓN MAYO, Isabel; TARDIF, Maurice. (Coord.). Identidad profesional docente. Madrid: Narcea Ediciones, 2018, p. 57-73.

PIMENTA, Selma Garrido. Formação de professores: identidade e saberes da docência. In: PIMENTA, Selma Garrido. (Org.). Saberes pedagógicos e atividade docente. 4. ed. São Paulo: Cortez, 2005, p. 15-34.

PIMENTA, Selma Garrido; LIMA, Maria Socorro Lucena. Estágio e docência. 7. ed. São Paulo: Cortez, 2012.

PINEAU, Gaston. A autoformação no decurso da vida: entre a hetero e a ecoformação. In: NÓVOA, António; FINGER, Matthias. (Org.). O método (auto)biográfico e a formação. Tradução de Maria Nóvoa. 2. ed. Natal: EdUFRN, 2014, p. 91-109.

RODRIGUES, Paulo Henrique; CYRINO, Márcia Cristina de Costa Trindade. A identidade profissional na formação inicial de professores de Matemática. In: DE PAULA, Enio Freire; CYRINO, Márcia Cristina de Costa Trindade. (Org.). Identidade profissional de professores que ensinam Matemática em contextos de formação. São Paulo: Pimenta Cultural, 2020, p. 69-95.

SOCIEDADE BRASILEIRA DE EDUCAÇÃO MATEMÁTICA (SBEM). Subsídios para a discussão de propostas para os cursos de Licenciatura em Matemática: uma contribuição da Sociedade Brasileira de Educação Matemática. Brasília: SBEM, 2003.

TARDIF, Maurice. Saberes docentes e formação profissional. Tradução de Francisco Pereira. 17. ed. Petrópolis: Vozes, 2014.

TEIXEIRA, Bruno Rodrigo; CYRINO, Márcia Cristina de Costa Trindade. O estágio de observação e o desenvolvimento da identidade profissional docente de professores de Matemática em formação inicial. Educação Matemática Pesquisa, São Paulo, v. 16, n. 2, p. 599-622, maio/ago. 2014.

TEIXEIRA, Bruno Rodrigo; CYRINO, Márcia Cristina de Costa Trindade. O Estágio de Regência como contexto para o desenvolvimento da identidade profissional docente de futuros professores de Matemática. Alexandria, Florianópolis, v. 8, n. 3, p.131-149, nov. 2015a.

TEIXEIRA, Bruno Rodrigo; CYRINO, Márcia Cristina de Costa Trindade. O estágio supervisionado como oportunidade de desenvolvimento profissional para futuros professores de Matemática. In: LOPES, Celi Espasandin; TRALDI JR., Armando; FERREIRA, Ana Cristina. (Org.). O Estágio na formação inicial do professor que ensina matemática. Campinas, SP: Mercado de Letras, 2015b, p. 81-112.

YIN, Robert K. Pesquisa qualitativa do início ao fim. Tradução de Daniel Bueno. Porto Alegre: Penso, 2016. 